\title{
The evolution of Malaysian banking sector's efficiency during financial duress: consequences, concerns, and policy implications
}

\begin{abstract}
By employing the non-stochastic data envelopment analysis (DEA) method, the present paper provides empirical evidence on the efficiency of the Malaysian banking sector around the Asian financial crisis. The empirical findings suggest that the foreign banks (FB) have exhibited higher technical efficiency (TE) compared to their domestic bank counterparts. However, the results suggest that the FB were severely affected by the Asian financial crisis, implying that the FB were not insulated from unexpected events like the Asian financial crisis of 1997.
\end{abstract}

Keyword: Bank efficiency; Data envelopment analysis; DEA; Panel regression analysis; Malaysia 